\title{
Wavelength conversion devices
}

Mikkelsen, Benny; Durhuus, Terji; Jørgensen, Carsten; Danielsen, Søren Lykke; Pedersen, Rune Johan Skullerud; Stubkjær, Kristian

\section{Published in:}

Proceedings of the Optical Fiber Communications Conference

Link to article, DOI:

10.1109/OFC.1996.907696

Publication date:

1996

Document Version

Publisher's PDF, also known as Version of record

Link back to DTU Orbit

Citation $(A P A)$ :

Mikkelsen, B., Durhuus, T., Jørgensen, C., Danielsen, S. L., Pedersen, R. J. S., \& Stubkjær, K. (1996).

Wavelength conversion devices. In Proceedings of the Optical Fiber Communications Conference (pp. 121-122). IEEE. https://doi.org/10.1109/OFC.1996.907696

\section{General rights}

Copyright and moral rights for the publications made accessible in the public portal are retained by the authors and/or other copyright owners and it is a condition of accessing publications that users recognise and abide by the legal requirements associated with these rights.

- Users may download and print one copy of any publication from the public portal for the purpose of private study or research.

- You may not further distribute the material or use it for any profit-making activity or commercial gain

- You may freely distribute the URL identifying the publication in the public portal 


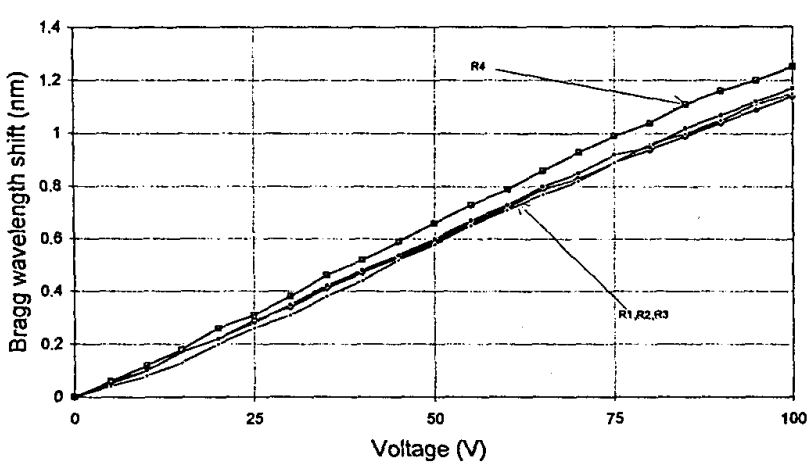

WF6 Fig. 2. Bragg wavelength shift w.r.t. voltage applied to the piezostack.

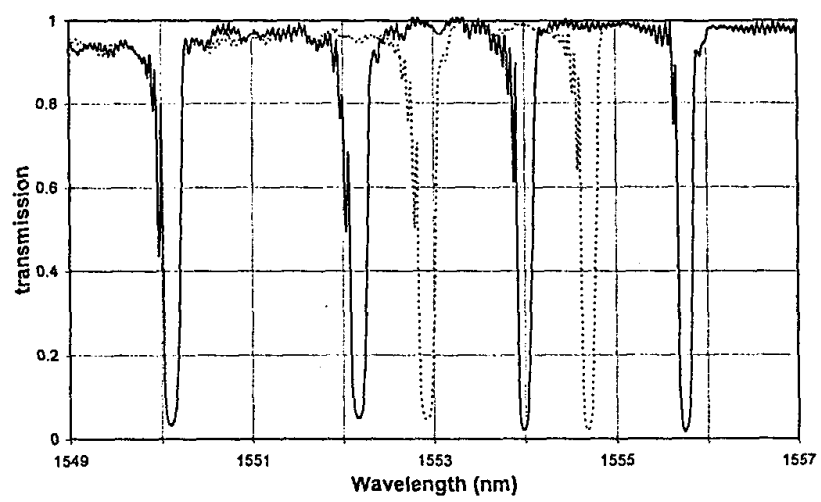

WF6 Fig. 3. Transmission spectrum of the set of four grating at rest (bold line) and with $25 \mathrm{~V}$ applied to actuators 2 and 3 (dotted line).

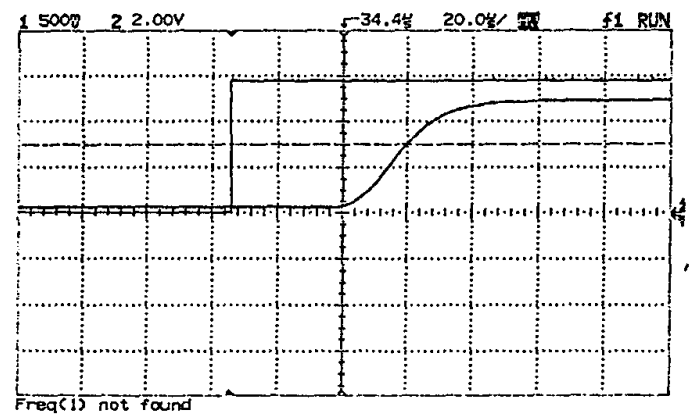

WF6 Fig. 4. Dynamics of channel switching (control signal and optical signal on output 2). Horizontal scale $20 \mu \mathrm{s} /$ div.

transmitted at output 1 when applying 25 Volts. The experimental curve is displayed on Fig. 4 (control signal and output optical level). The switching time is limited by the electrical response of the amplifier and by the piezostack response. In the case shown on Fig. 4, one observes a delay of $40 \mu$ s between the electric control signal and the beginning of switching, and a switching time $(10 \%-90 \%)$ of $30 \mu \mathrm{s}$. The main source of insertion losses and polarization dependence of this device is the circulator. Insertion losses are of course dependent on the output port, but with a three-port circulator they do not exceed 3 $\mathrm{dB}$ in the worst case (output 2).

In conclusion, we have demonstrated that piezoactuated gratings can be combined to build active demultiplexers or wavelengths routers. With minor modifications, this device can operate as a programmable add and drop multiplexer.

1. S. P. Fang and H. F. Taylor, "High-performance singlemode fiber-optic switch," Opt. Lett. 19, 1204-1206 (1994).

2. L. Quetel, J. Le Mellot, H. Poignant, L. Rivoallan, E. Delevaque, and $M$. Monerie, "Step-tunable fiber optic delay line," in ECOC'95, 18-20 September 1995, Brussels, Belgium, paper TuP09.

WG

\section{Wavelength Conversion}

1:00 pm-3:00 pm Room A2

Jay Martin Wiesenfeld, AT\&T Bell Laboratories, Presider

WG1 (Invited) 1:00 pm

\section{Wavelength conversion devices}

B. Mikkelsen, T. Durhuus, C. Joergensen, S. L. Danielsen, R. J. S. Pedersen, K. E. Stubkjaer, Center for Broadband Telecommunications, Technical University of Denmark, DK-2800 Lyngby, Denmark

Wavelength converters will be essential devices to exploit the full potential of the wavelength dimension in wavelength-division multiplexed (WDM) networks. Their most important use will be: to avoid wavelength blocking in optical cross-connects, to allow wavelength paths to be allocated on a link by link basis thereby facilitating simpler network reconfiguration, protection switching, and wavelength referencing, and to perform routing functions together with optical filters (e.g., space switching in optical switches). Based on experiments, we discuss different candidates for efficient wavelength converters with attention to expected system requirements.

The ideal wavelength converter should be transparent to the bit rate and signal format and provide an unchirped output signal with both a high extinction ratio and a large signal-tonoise ratio. It should allow conversion to both shorter and longer wavelengths with equal performance and operate at practical input power levels. A simple implementation is also very important.

Today, no conversion device fulfills all the requirements. Nevertheless, many promising techniques have been proposed and demonstrated. The straightforward implementation is an electro-optic converter consisting of a front-end followed by a transmitter, that retransmits the incoming signal on a new wavelength. However, disadvantages such as complexity and large power consumption have directed the interest towards all-optical wavelength converters, that permit conversion without translating the signal to the electrical domain. Examples of all-optical wavelength conversion devices that will be discussed in this talk are (see Fig. 1): cross-gain modulation (XGM) and cross-phase modulation (XPM) in semiconductor optical amplifiers (SOAs), four-wave mixing (FWM) in SOAs or optical fibers, and optical modulation of different types of 


\section{A)}
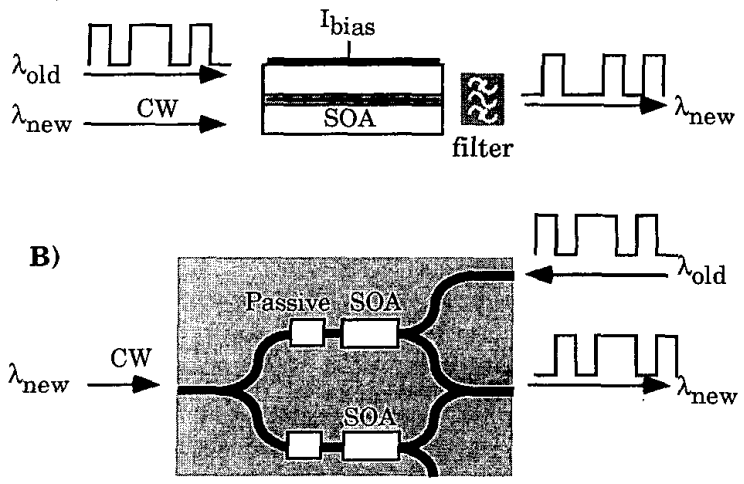

C)
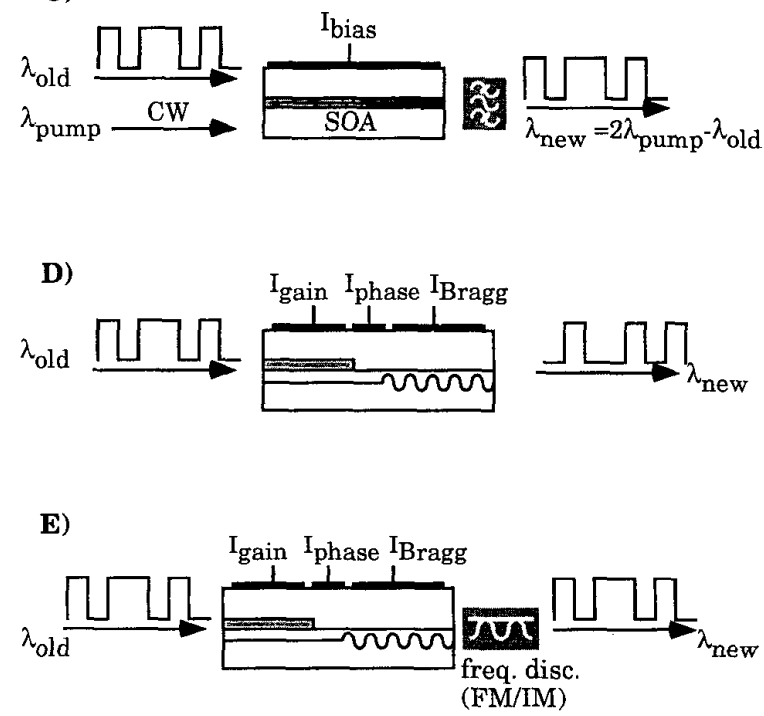

WG1 Fig. 1. Different all-optical conversion devices. A) cross-gain modulation in SOA (note that signal and cw can be counter-coupled eliminating need for filtering); B) cross-phase in SOAs being part of an integrated interferometer (e.g., MZI); C) four-wave mixing in SOA (2 pumps are required for polarization independence); D) cross-gain modulation of laser (e.g., DFB, DBR, or Y-laser); E) cross-frequency modulation of laser (e.g., DFB, DBR, or Y-laser) followed by a frequency discriminator (e.g., MZI).

lasers. Although not given here, the presentation will describe experiments and the operation principle for the different conversion devices. Moreover, this talk intends to focus on the performance and the development, that is required for each conversion device to be attractive for short and long term applications.

Converters relying on XGM or XPM in SOAs are relatively simple converters, that presently allow polarization-insensitive conversion at data rates of more than $10 \mathrm{Gbit} / \mathrm{s}$ (NRZ). To increase the speed capability, the SOA-structure should feature a small transverse mode area (high confinement factor), which allows high current injection (e.g., long device length and/or quantum well (QW) material). For short term applications of converters, however, control of XPM-converters (interferomet-
WG1 Table 1. Short-term and long-term requirements and performance of different conversion devices.

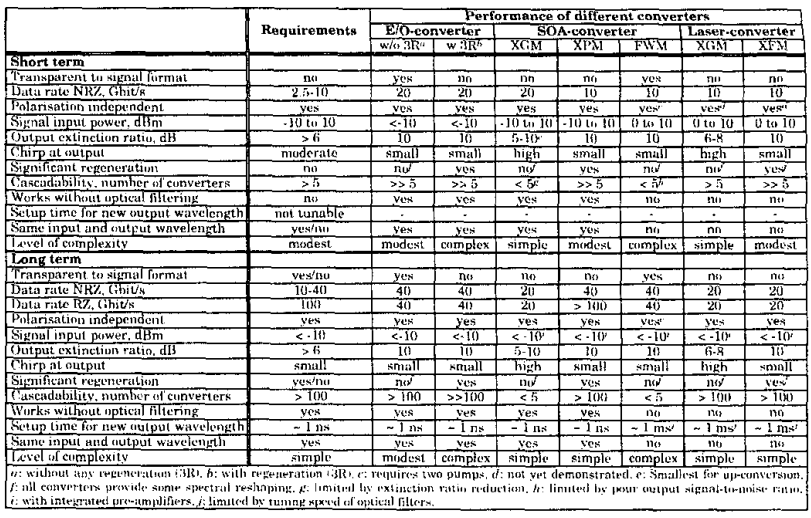

ric structures) must be addressed. For that purpose, the XPMconverters should be implemented with passive phase sections enabling simpler control schemes [see Fig. 1(B)].

Wavelength converters relying on FWM suffer from a pour efficiency, the inherent polarization sensitivity of the FWM-process, and the inevitable need for strong optical output filtering. To increase the FWM-efficiency (to obtain a higher output signal-to-noise ratio), the same SOA-structure as needed for the speed optimization of XGM and XPM-converters has to be developed.

Cross-gain and cross-frequency modulation (XFM) of different lasers have been exploited for wavelength conversion of 5-10 Gbit/s data. To make these converters feasible, they have to be realized with polarization-insensitive gain sections while maintaining single mode operation. For the high performance laser converters relying on XFM, the laser and the frequency discriminator should be integrated.

All converter devices addressed here require relatively high input powers to allow conversion of high data rates. Therefore, it would be desirable to integrate the different converter structures with optical pre-amplifiers.

Finally, general characteristics of the different converter devices are summarized in Table 1 . The presentation will include a more in-depth discussion of the data. It should, however, be emphasized, that a comparison of the different conversion devices is not straightforward, considering the many possible applications of optical wavelength converters and the continuous progress in the field.

WG2 $1: 30 \mathrm{pm}$

\section{$10 \mathrm{Gbit} / \mathrm{s}$ monolithic MQW-based wavelength converter in Michelson interferometer configuration}

M. Schilling, W. Idler, G. Laube, K. Daub, K. Dütting, E. Lach, D. Baums, K. Wünstel, Alcatel Corporate Research Center, Stuttgart Optoelectronic Components Division ZFZ/WO, Lorenzstr. 10, D-70435 Stuttgart, Germany

Efficient and stable high-speed wavelength conversion is a key function required in optical routing and switching systems. To overcome extinction ratio (ER) degradation and BER deterio- 